\title{
Synthesis and antiviral activities of spacer-linked 1-thioglucuronide analogues of glycyrrhizin
}

\author{
Christian Stanetty ${ }^{1, \S}$, Andrea Wolkerstorfer ${ }^{2, \S}$, Hassan Amer ${ }^{1}$, \\ Andreas Hofinger ${ }^{1}$, Ulrich Jordis ${ }^{3}$, Dirk Claßen-Houben ${ }^{2}$ and Paul Kosma ${ }^{* 1}$
}

\section{Full Research Paper}

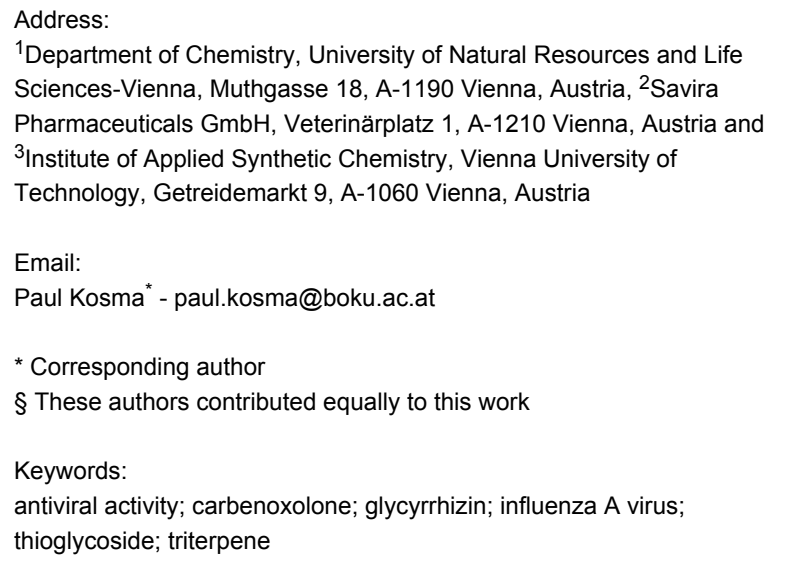

Beilstein J. Org. Chem. 2012, 8, 705-711. doi:10.3762/bjoc. 8.79

Received: 09 March 2012

Accepted: 12 April 2012

Published: 08 May 2012

This article is part of the Thematic Series "Synthesis in the glycosciences II".

Guest Editor: T. K. Lindhorst

(c) 2012 Stanetty et al; licensee Beilstein-Institut. License and terms: see end of document.

\begin{abstract}
The influenza virus infection remains a significant threat to public health and the increase of antiviral resistance to available drugs generates an urgent need for new antiviral compounds. Starting from the natural, antivirally active compound glycyrrhizin, spacerbridged derivatives were generated with improved antiviral activity against the influenza A virus infection. Simplified analogues of the triterpene saponin glycyrrhizin containing 1-thio- $\beta$-D-glucuronic acid residues have been prepared in good yields by alkylation of 3-amino and 3-thio derivatives of glycyrrhetinic acid with a 2-iodoethyl 1-thio- $\beta$-D-glucopyranosiduronate derivative. The spacer-connected 3-amino derivatives were further transformed into $\mathrm{N}$-acetylated and $\mathrm{N}$-succinylated derivatives. The deprotected compounds containing these carboxylic acid appendices mimic the glycon part of glycyrrhizin as well as the hemisuccinate derivative of glycyrrhetinic acid, carbenoxolone. Antiviral activities of the compounds were determined in a biological test based on influenza A virus-infected cells, wherein the 3-(2-thioethyl)- $N$-acetylamino- and 3-(2-thioethyl)-thio-linked glucuronide derivatives were effective inhibitors with $\mathrm{IC}_{50}$ values as low as $54 \mu \mathrm{M}$.
\end{abstract}

\section{Introduction}

The triterpene saponin glycyrrhizin (GL) and its aglycon glycyrrhetinic acid (GA) are the main triterpene components of licorice roots and harbor various pharmacological activities, including antitumor, anti-inflammatory, antioxidant and antiviral properties $[1,2]$. The antiviral activities have been reported to be directed against a broad spectrum of viruses comprising herpes-, corona-, alpha-, and flaviviruses, HIV, Epstein-Barr virus, influenza A virus (IAV), vaccinia and 


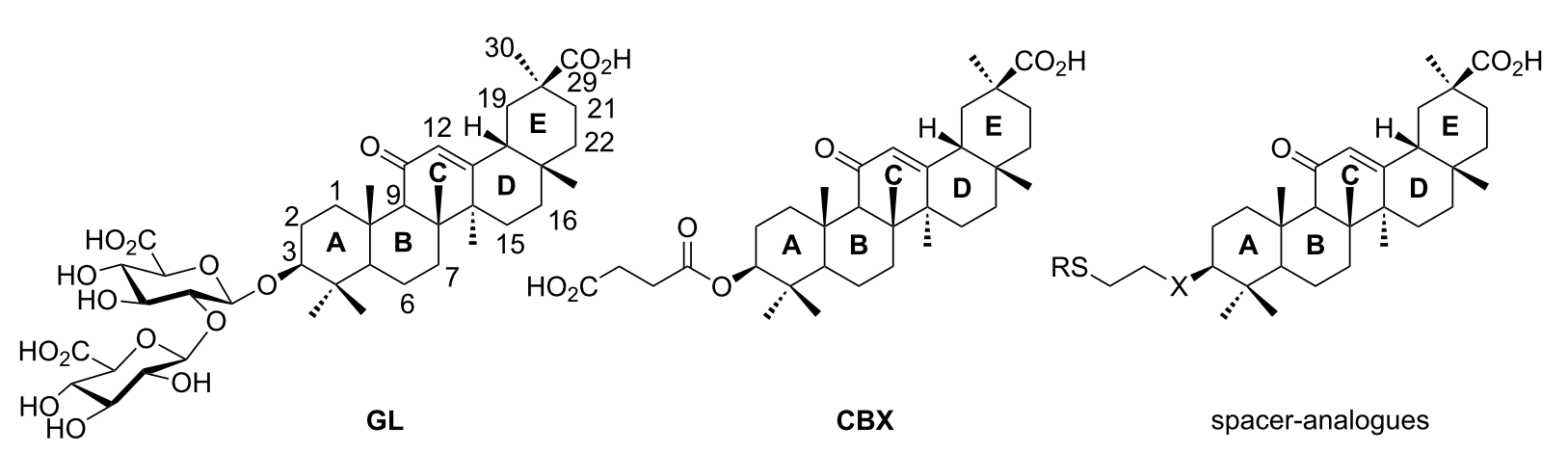

Figure 1: Structure of glycyrrhizin (GL), carbenoxolone (CBX), and spacer analogues.

polio type I viruses as examples [3-8]. In particular antiinfluenza virus activities have been described, although the underlying mechanisms of action are diverse [9-12]. In order to evaluate the potential antiviral properties of glycyrrhizin derivatives, we set out to modify the chemical environment in the vicinity of ring A of glycyrrhetinic acid. The envisaged modifications should assess the impact of acidic groups, which reside at the glucuronic acid residues in the $\beta$ - $(1 \rightarrow 2)$-linked disaccharide unit of $\mathbf{G L}$, with respect to antiviral properties (Figure 1).

Previously, ring A modified derivatives of glycyrrhetinic acid were prepared containing 3-amino, 3-thio and 1-thio groups, allowing for an extension of the oleanolic acid unit with spacer groups as well as facile covalent attachment of carboxyalkyl groups by alkylation or acylation reactions $[13,14]$. For the compounds included in this investigation, the size of the spacer group was selected to closely match the formal distances between the A-ring and the carboxylic acid function present in the glucopyranosiduronic residues of the parent compound glycyrrhizin (GL) and in the hemisuccinate moiety of the glycyrrhetinic acid derivative carbenoxolone (CBX) [15] (Figure 1). For the sake of clarity, the nomenclature and numbering for the triterpene system as used throughout this report is illustrated in Figure 1. In order to enhance resistance against enzymatic cleavage by glucuronidases, the glucuronic acid residue was introduced through a stable thioglycosidic linkage.

\section{Results and Discussion \\ Synthesis of 3-amino derivatives}

Commercially available methyl (2,3,4-tri- $O$-acetyl-D-glucopyranosyl)uronate bromide (1) was first reacted with potassium thioacetate in DMF to furnish the known 1-thioacetyl derivative $\mathbf{2}$ in $82 \%$ yield [16]. Subsequent treatment of $\mathbf{2}$ with sodium methoxide, under controlled conditions at low temperature $\left(-60{ }^{\circ} \mathrm{C} \rightarrow-45{ }^{\circ} \mathrm{C}\right)$, provided the corresponding glucuronyl 1 -thiol $\mathbf{3}$ in $89 \%$ yield $[17,18]$. Reaction of $\mathbf{3}$ with an excess of 1,2-dibromoethane (3-4 equiv) in DMF in the presence of sodium hydride, with the strict exclusion of oxygen, afforded the 2-bromoethyl 1-thioglycoside 4 in $80 \%$ yield. Under these conditions formation of the bis-substitution product 5 (3\%) and the disulfide oxidation product of 1-thiol 3 was observed in only very minor quanities. The corresponding 2 -iodoethyl derivative 6 was prepared by a Finkelstein reaction from the bromoethyl 1-thioglycoside 4 in $95 \%$ yield (Scheme 1).

The previously reported $3 \beta$-amino derivative of the diphenylmethyl ester of glycyrrhetinic acid 7 [19] was then used for the introduction of the spacer-extended 1-thio-glucopyranosiduronate residue. Coupling of the $3 \beta$-amino derivative 7 with two equivalents of the 2-iodoethyl glycoside 6 in DMF in the presence of Hünig base proceeded smoothly to provide the alkylated amine $\mathbf{8}$ in $79 \%$ yield without the formation of a bisalkylated product (Scheme 2), whereas the use of the corresponding bromide 4 resulted in a significantly slower reaction.

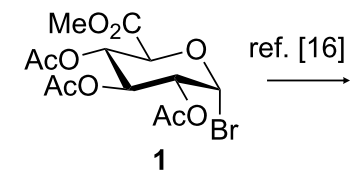

1

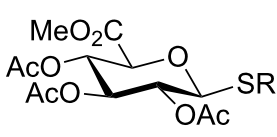

(a) $\left\{\begin{array}{l}2 \mathrm{R}=\mathrm{Ac} \\ 3 \mathrm{R}=\mathrm{H}\end{array}\right.$ (b)
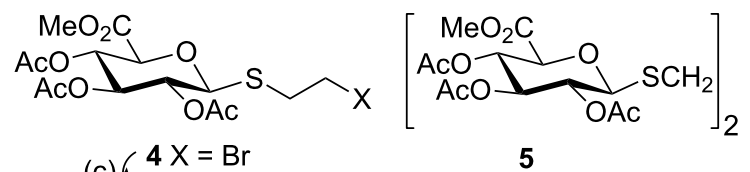

5 


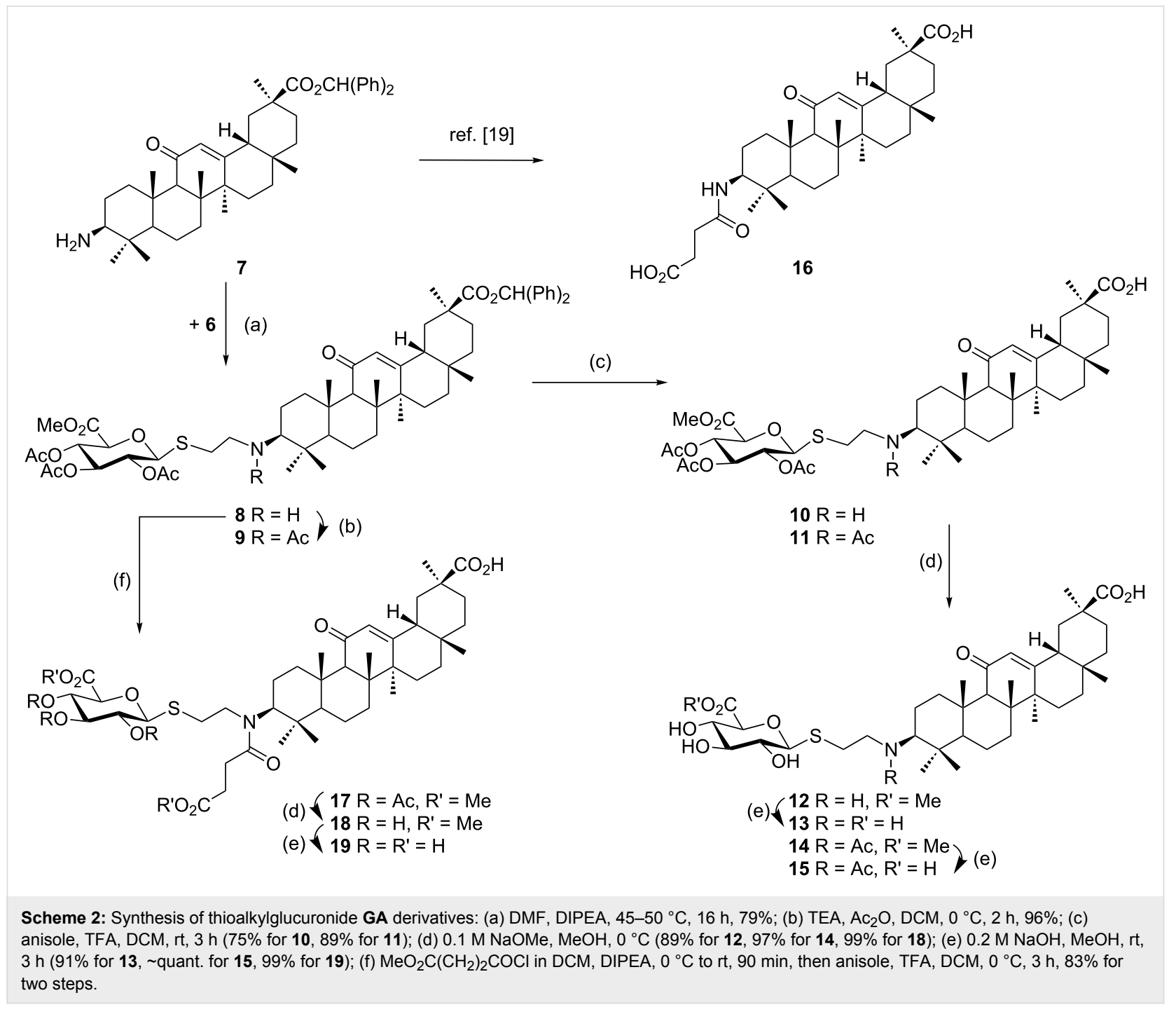

At elevated temperature, elimination leading to the corresponding hexenuronic acid derivative was observed (structure not shown). The secondary amino group in compound $\mathbf{8}$ was subjected to further derivatization by $\mathrm{N}$-acetylation (triethylamine, acetic anhydride), which gave compound 9 in $96 \%$ yield. Deprotection of the ethyl 1-thio-glucuronide derivatives 8 and 9 was achieved by acid-catalyzed cleavage of the diphenylmethyl ester group with TFA/anisole (as carbocation scavenger), giving the monoacid derivatives $\mathbf{1 0}$ and $\mathbf{1 1}$ in $\mathbf{7 5 \%}$ and $89 \%$ yield, respectively. Subsequent transesterification of $\mathbf{1 0}$ and $\mathbf{1 1}$ with methanolic NaOMe afforded the deacetylated methyl ester glucuronide derivatives 12 and 14, respectively, which were finally fully deprotected by hydrolysis of the methyl ester group with $0.2 \mathrm{M}$ methanolic $\mathrm{NaOH}$ to furnish the diacid derivatives 13 and $\mathbf{1 5}$, in high overall yield.

A second series of compounds was designed as glucuronideextended amide derivatives of the previously reported carbenoxolone analogue $\mathbf{1 6}$ [20,21]. Reaction of the 3 -amino group of $\mathbf{8}$ with the monomethyl ester of succinic acid chloride in dichloromethane in the presence of Hünig base was followed by deblocking of the diphenylmethyl ester group to afford $\mathbf{1 7}$ in a combined yield of $83 \%$. The acetyl groups of 17 were removed under Zemplén conditions to afford the dimethyl ester 18. Alkaline hydrolysis of the ester groups eventually gave the triacid derivative $\mathbf{1 9}$ in good yield. In contrast to the straightforward chemical transformations, analysis of the NMR spectra of this series of compounds was challenging and the $\mathrm{N}$-acylated derivatives $9,11,14,15$ and 17-19 revealed complex spectra. Whereas the secondary amides of $3 \beta$-amino-glycyrrhetinic acid derivatives displayed coherent NMR signals [22,23], the tertiary amides frequently exist as mixtures of cis/trans rotamers leading to the duplication of signals $[24,25]$. The steric congestion at position 3 exerted by the two adjacent methyl groups may additionally contribute to the restricted rotation of the amide linkage. Thus, in the ${ }^{1} \mathrm{H}$ NMR spectra of the $N$-acetyl- 


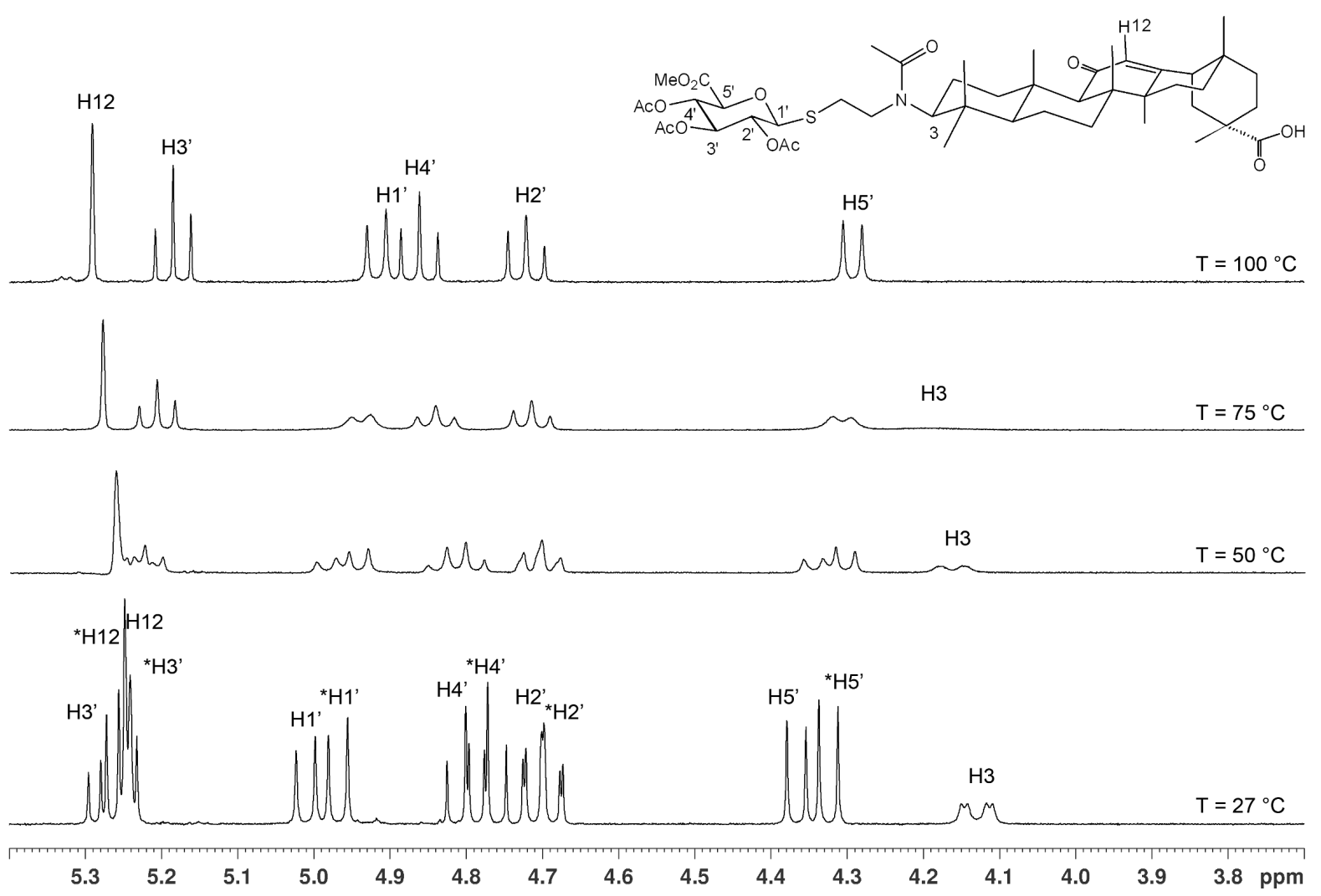

Figure 2: $400 \mathrm{MHz}{ }^{1} \mathrm{H}$ NMR expansion plots of the carbohydrate region of compound 11 , recorded at various temperatures.

and $N$-succinyl derivatives, recorded at room temperature, two sets of signals in an approximate $6: 4$ ratio were observed. Reversible coalescence of these signal groups was observed upon heating a solution of the $\mathrm{N}$-acetyl derivative 11 up to $100{ }^{\circ} \mathrm{C}$ in DMSO- $d_{6}$ and subsequent cooling to room temperature (Figure 2), supporting the assignment of two signal data sets for two rotamers. The orientation of the amide carbonyl group in the rotamers also had a pronounced effect on the NMR chemical shifts of carbon and proton signals in ring A, which led to a shift of H-3 to lower field ( $\delta 4.47)$ and to a shielding of C-3 $(\delta 59.9)$ for the minor isomer, whereas the inverse effects were seen for the major rotamer ( $\delta$ for $\mathrm{H}-3$ at 3.36 and $\delta$ for C-3 at 66.7). Similar, but less-pronounced effects were observed for the respective ${ }^{1} \mathrm{H}$ and ${ }^{13} \mathrm{C}$ signals at position 5 of ring A (see Supporting Information File 1).

\section{Synthesis of 3-thio derivatives}

Complementing the series of the $3 \beta$-amino series, related 3 -thio derivatives were employed for the spacer elongation [14]. The previously reported 1,2-dehydro-3-thiol derivative $\mathbf{2 0}$ was subjected to alkylation with the 2-iodoethyl 1-thioglucuronide compound 6 in the presence of $\mathrm{K}_{2} \mathrm{CO}_{3}$ to furnish the thioetherbridged glucuronide triterpene $\mathbf{2 1}$ in $60 \%$ yield. Deprotection of
21 was performed in two steps as described for 10, which furnished the methyl ester derivative $\mathbf{2 2}$ and the glucuronic acid compound 23, respectively, in good yields (Scheme 3).

\section{Antiviral activities}

For biological testing the compounds were dissolved in DMSO and diluted in cell culture medium to a maximum final DMSO concentration of $1 \%$. For determination of the cytotoxicity of the compounds, MDCK cells were treated with compound concentrations ranging from $3.1 \mu \mathrm{M}$ to $250 \mu \mathrm{M}$ for $48 \mathrm{~h}$ and then cell viability was determined as a surrogate endpoint for cytotoxicity. Except for the aglycons of GL, namely glycyrrhetinic acid (GA) and the hemisuccinate carbenoxolone (CBX), which showed $\mathrm{CC}_{50}$ values (half-maximal cytotoxic concentration) of $7.4 \mu \mathrm{M}$ and $17.8 \mu \mathrm{M}$, respectively, none of the compounds tested were toxic at concentrations up to $250 \mu \mathrm{M}$. GL was not toxic at $2500 \mu \mathrm{M}$ (Table 1). The antiviral activity of the compounds was determined by infecting MDCK cells with influenza A H3N2 virus and treating them with different concentrations of compounds at the same time. Most compounds prevented virus-induced cytopathicity and restored cell viability compared to virus-infected control cells. The antiviral activity of glycyrrhizin (GL) against influenza and other viruses 


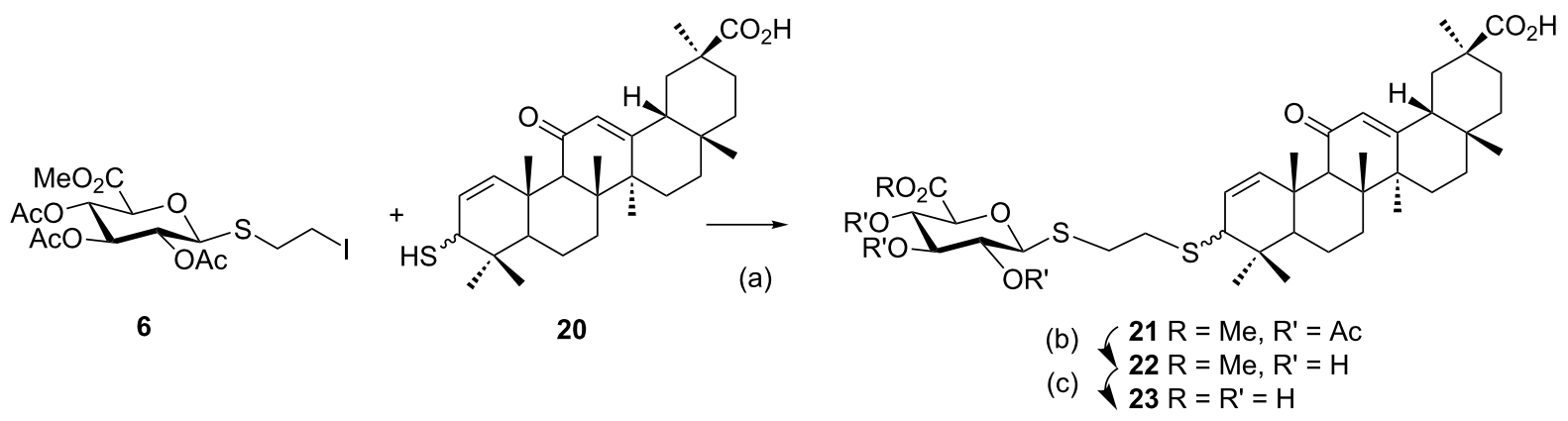

Scheme 3: Synthesis of 3-thioether-bridged glucuronide derivatives: (a) $\mathrm{K}_{2} \mathrm{CO}_{3}$, acetone, $60 \%$; (b) $0.8 \mathrm{M} \mathrm{NaOMe}, \mathrm{MeOH}, 71 \%$; (c) $0.2 \mathrm{M} \mathrm{NaOH}$, $\mathrm{MeOH}, 95 \%$

reported in the literature was confirmed in this study resulting in an $\mathrm{IC}_{50}$ of $1026 \mu \mathrm{M}$ (Table 1). GA and $\mathbf{C B X}$ did not show any antiviral activity at nontoxic concentrations. Compounds 12, 13, $14,15,18$ and 19, which possess a (1-thio- $\beta$-D-glucopyranosyluronic acid)ethylamino substituent at position 3 of $\mathbf{G A}$ did not show toxicity at concentrations up to $250 \mu \mathrm{M}$, but showed enhanced antiviral activity compared to GL. Good activities were found for compounds $\mathbf{1 2}$ and $\mathbf{1 8}$ with $\mathrm{IC}_{50}$ values of $220.4 \mu \mathrm{M}$ and $125 \mu \mathrm{M}$, respectively, being between 4.7 -fold to 8 -fold more active compared to the lead compound GL. The methyl ester 14 containing the $\mathrm{N}$-acetylated spacer group was approximately 14-fold more active compared to GL, reflected by an $\mathrm{IC}_{50}$ value of $72.1 \mu \mathrm{M}$. The free acid $\mathbf{1 5}$ displayed an $\mathrm{IC}_{50}$ value in the same range as the methyl ester 14. Replacement of the $\mathrm{N}$-acetyl group of $\mathbf{1 4}$ with a methylsuccinyl group
(18) did not improve the activity; however, the compound was still active with an $\mathrm{IC}_{50}$ value of $125 \mu \mathrm{M}$. The cleavage of both methyl ester groups of this compound resulted in compound 19 and led to the loss of antiviral activity up to the highest concentration tested $(250 \mu \mathrm{M})$. Compound $\mathbf{1 6}$ containing only the $N$-succinyl substituent is a close analogue to $\mathbf{C B X}$ bearing an amide instead of the ester group. Unlike CBX, which is toxic at low concentrations, $\mathbf{1 6}$ was not toxic but inactive, indicating that the glucuronic acid moiety is associated with the antiviral properties. This was further supported by the data obtained with compound $\mathbf{2 3}$ containing a 1-thioethyl-linked glucuronic acid residue at position 3 of 1,2-dehydro-glycyrrhetinic acid. Compound 23 showed good activity with an even lower $\mathrm{IC}_{50}$ value of $54 \mu \mathrm{M}$ compared to $\mathbf{1 5}$, and exhibited also no cytotoxicity at the concentrations tested.

Table 1: Cytotoxic concentration $50 \%\left(\mathrm{CC}_{50}\right)$ of compound-treated uninfected cells and antiviral activities, shown as half-maximal inhibitory concen-
tration $\left(\mathrm{I}_{50}\right)$ values of glycyrrhizin $(\mathrm{GL})$ analogues.
Compound


Table 1: Cytotoxic concentration $50 \%\left(\mathrm{CC}_{50}\right)$ of compound-treated uninfected cells and antiviral activities, shown as half-maximal inhibitory concentration $\left(\mathrm{IC}_{50}\right)$ values of glycyrrhizin $(\mathrm{GL})$ analogues. (continued)

13

14

15

16<smiles>CC[C@H](C)NCCSC1OC2CC(C)(O)C(O)C(O)C(O)C1O2</smiles><smiles>CCC(C)N([14CH3])CCSC12OC(COC)C(O)C(O)C(O1)C(O)C2O</smiles>

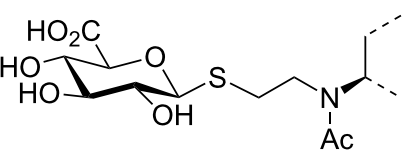<smiles>CCC(C)N(CCSC1OC(C)C(O)C(O)C1OC)C(=O)CCC(C)OC</smiles><smiles>CCC(C)N(CCSC1OC(C)C(O)C(O)C1O)C(=O)CCC(=O)O</smiles>

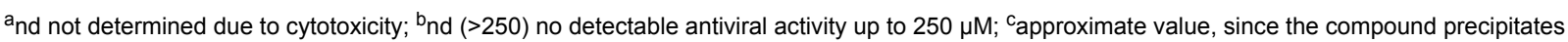
at concentrations $>75 \mu \mathrm{M}$.

\section{Conclusion}

3-Amino and 3-thio derivatives of glycyrrhetinic acid served as versatile scaffolds for the attachment of glycosyl extensions through high-yielding alkylation reactions. The glucuronide derivatives linked via a thioethyl spacer group to the oleanolic acid unit exhibited no toxicity at concentrations up to $250 \mu \mathrm{M}$ and significantly enhanced the anti-influenza virus activity of the natural triterpene glycoside glycyrrhizin.

\section{Supporting Information}

\section{Supporting Information File 1}

Experimental details for the preparation of compounds

2-19 and 21-23 as well as the biological assays.

[http://www.beilstein-journals.org/bjoc/content/ supplementary/1860-5397-8-79-S1.pdf]

\section{Acknowledgements}

The work was supported by the ZIT Zentrum für Innovation und Technologie GmbH (Vienna Spot of Excellence: 182081). We thank Michaela Mutzl, Barbara Butzendobler and Eva Zingler for the performance of antiviral activity assays and David Baum and Karin Hofbauer for technical assistance in the organic syntheses of precursors.

\section{References}

1. Baltina, L. A. Curr. Med. Chem. 2003, 10, 155-171.

2. Schwarz, S.; Csuk, R. Bioorg. Med. Chem. 2010, 18, 7458-7474. doi:10.1016/j.bmc.2010.08.054

3. Lampis, G.; Deidda, D.; Pinza, M.; Pompei, R. Antiviral Chem. Chemother. 2001, 12, 125-131.

4. Cinatl, J.; Morgenstern, B.; Bauer, G.; Chandra, P.; Rabenau, H.; Doerr, H. W. Lancet 2003, 361, 2045-2046. doi:10.1016/S0140-6736(03)13615-X 
5. Crance, J. M.; Scaramozzino, N.; Jouan, A.; Garin, D. Antiviral Res. 2003, 58, 73-79. doi:10.1016/S0166-3542(02)00185-7

6. Hattori, T.; Ikematsu, S.; Koito, A.; Matsushita, S.; Maeda, Y.; Hada, M.; Fujimaki, M.; Takatsuki, K. Antiviral Res. 1989, 11, 255-261. doi:10.1016/0166-3542(89)90035-1

7. Harada, S. Biochem. J. 2005, 392, 191-199. doi:10.1042/BJ20051069

8. Lin, J.-C. Antiviral Res. 2003, 59, 41-47. doi:10.1016/S0166-3542(03)00030-5

9. Pompei, R.; Paghi, L.; Ingianni, A.; Uccheddu, P. Microbiologica 1983, 6, 247-250.

10. Utsunomiya, T.; Kobayashi, M.; Pollard, R. B.; Suzuki, F. Antimicrob. Agents Chemother. 1997, 41, 551-556.

11. Wolkerstorfer, A.; Kurz, H.; Bachhofner, N.; Szolar, O. Antiviral Res. 2009, 83, 171-178. doi:10.1016/j.antiviral.2009.04.012

12. Michaelis, M.; Geiler, J.; Naczk, P.; Sithisarn, P.; Leutz, A.; Doerr, H. W.; Cinatl, J., Jr. PLoS One 2011, 6, e19705. doi:10.1371/journal.pone.0019705

13. Claßen-Houben, D.; Kueenburg, B.; Kosma, P.; Jordis, U.; Stanetty, C.; Szolar, O.; Wolkerstorfer, A. Antiviral Triterpene Derivatives. EP 2258 713 A1, Dec 8, 2010.

14. Amer, H.; Mereiter, K.; Stanetty, C.; Hofinger, A.; Czollner, L.; Beseda, I.; Jordis, U.; Kueenburg, B.; Claßen-Houben, D.; Kosma, P. Tetrahedron 2010, 66, 4390-4402. doi:10.1016/j.tet.2010.03.098

15. Jellinck, P. H.; Monder, C.; McEwen, B. S.; Sakai, R. R. J. Steroid Biochem. Mol. Biol. 1993, 46, 209-213. doi:10.1016/0960-0760(93)90296-9

16. Florio, P.; Thomson, R. J.; von Itzstein, M. Carbohydr. Res. 2000, 328, 445-448. doi:10.1016/S0008-6215(00)00228-7

17. MacDougall, J. M.; Zhang, X.-D.; Polgar, W. E.; Khroyan, T. V.; Toll, L.; Cashman, J. R. J. Med. Chem. 2004, 47, 5809-5815. doi:10.1021/jm049554t

18. Cao, H.; Yu, B. Tetrahedron Lett. 2005, 46, 4337-4340. doi:10.1016/j.tetlet.2005.04.088

19. Beseda, I.; Czollner, L.; Shah, P. S.; Khunt, R.; Gaware, R.; Kosma, P.; Stanetty, C.; del Ruiz-Ruiz, M. C.; Amer, H.; Mereiter, K.;

Da Cunha, T.; Odermatt, A.; Claßen-Houben, D.; Jordis, U. Bioorg. Med. Chem. 2010, 18, 433-454. doi:10.1016/j.bmc.2009.10.036

20. ljichi, S.; Tamagaki, S. Chem. Lett. 2005, 34, 356-357. doi:10.1246/cl.2005.356

21. Brieskorn, C. H.; Eschelbach, H. Arch. Pharm. 1979, 312, 752-762. doi:10.1002/ardp.19793120907

22. Stanetty, C.; Czollner, L.; Koller, I.; Shah, P.; Gaware, R.; Da Cunha, T.; Odermatt, A.; Jordis, U.; Kosma, P.; Claßen-Houben, D. Bioorg. Med. Chem. 2010, 18, 7522-7541. doi:10.1016/j.bmc.2010.08.046

23. Csuk, R.; Schwarz, S.; Siewert, B.; Kluge, R.; Ströhl, D. Eur. J. Med. Chem. 2011, 46, 5356-5369. doi:10.1016/j.ejmech.2011.08.038

24. Zhou, C. C.; Stewart, K. D.; Dhaon, M. K. Magn. Reson. Chem. 2005, 43, 41-46. doi:10.1002/mrc. 1501

25. Stewart, W. E.; Siddall, T. H., III. Chem. Rev. 1970, 70, 517-551. doi:10.1021/cr60267a001

\section{License and Terms}

This is an Open Access article under the terms of the Creative Commons Attribution License

(http://creativecommons.org/licenses/by/2.0), which permits unrestricted use, distribution, and reproduction in any medium, provided the original work is properly cited.

The license is subject to the Beilstein Journal of Organic Chemistry terms and conditions:

(http://www.beilstein-journals.org/bjoc)

The definitive version of this article is the electronic one which can be found at:

doi:10.3762/bjoc. 8.79 